\title{
LAZER E SAÚDE MENTAL EM TEMPOS DE COVID-19
}

Recebido em: 30/12/2020

Aprovado em: 17/02/2021

Licença:@) (1) @

Suzy Kamylla de Oliveira Menezes ${ }^{1}$

Universidade Federal de Alagoas (UFAL)

Instituto Federal de Alagoas (IFAL)

Maceió - AL - Brasil

RESUMO: A pandemia por COVID-19 trouxe grandes repercussões no cotidiano da população mundial, devido à necessidade de quarentena, isolamento e distanciamento social. Essas medidas mudaram as opções de lazer e tiveram repercussões sobre a saúde mental das pessoas. O objetivo deste trabalho é analisar como saúde mental e lazer foram impactados durante a pandemia por COVID-19. Para isso foi realizada uma revisão de literatura em artigos produzidos durante o ano de 2020. Os resultados mostram que as mudanças devido à pandemia afetaram a saúde mental da população no Brasil e no mundo. Os impactos negativos podem se manifestar pelo aumento de estresse, ansiedade e depressão, por exemplo. Para se adaptar à pandemia, as opções de lazer virtual foram as mais utilizadas nos estudos analisados. Conclui-se que a busca por estratégias que atenuem os impactos sobre a saúde mental e sobre o lazer são essenciais para lidar com a atual crise devido à pandemia.

PALAVRAS-CHAVE: Atividades de Lazer. Saúde Mental. COVID-19.

\section{LEISURE AND MENTAL HEALTH IN TIMES OF COVID-19}

ABSTRACT: The COVID-19 pandemic brought great repercussions on the lives of the world population, due to the need for quarantine, isolation and social distancing. These measures changed leisure options and had repercussions on people's mental health. This work aims to analyze how mental health and leisure were impacted during the COVID19 pandemic. For this, a literature review was carried out on articles produced during the year 2020. The results show that the changes due to the pandemic have affected the mental health of the population in Brazil and the world. Negative impacts can be manifested by increased stress, anxiety, and depression, for example. To adapt to the pandemic, virtual leisure options were the most used in the analyzed studies. It is concluded that the search for strategies that mitigate the impacts on mental health and leisure is essential to deal with the current crisis due to the pandemic.

KEYWORDS: Leisure Activities. Mental Health. COVID-19.

\footnotetext{
${ }^{1}$ Doutoranda em Educação pelo Centro de Educação (CEDU) da UFAL. Mestra em Informática pela UFAL. Graduada em Psicologia e Ciência da Computação pela UFAL. Professora do Instituto Federal de Alagoas (IFAL).
}

licere, Belo Horizonte, v.24, n.1, mar/2021. DOI: https://doi.org/10.35699/2447-6218.2021.31341 408 


\section{Introdução}

A pandemia por COVID-19 trouxe grandes repercussões no cotidiano da população mundial. Dentre as grandes mudanças na rotina das pessoas foram colocadas a necessidade de quarentena, isolamento social e distanciamento social. Tais medidas de controle para reduzir os índices de contaminação impactaram diretamente às opções de lazer e a saúde mental da população. Nesse contexto, observa-se a mudança em busca de adaptações para esse momento atípico, às quais também dependem de condições sociais, culturais e psicológicas de cada pessoa.

Em 11 de março de 2020, a pandemia pelo coronavírus 2019, conhecida por COVID-19 foi reconhecida pela Organização Mundial da Saúde (OMS). No Brasil, o primeiro caso foi confirmado em 26 de fevereiro de 2020 e através da Portaria $\mathrm{n}^{\circ} 454$, de 20 de março de 2020, foi declarado estado de transmissão comunitária do novo coronavírus (MINISTÉRIO DA SAÚDE, 2020; IMPRENSA NACIONAL, 2020).

Para conter a transmissão da doença, medidas de segurança passaram a ser divulgadas e exigidas para a população. Wilder-Smith e Freedman (2020) definem isolamento social como a separação de pessoas doentes com uma doença contagiosa de pessoas que não estão infectadas. Quarentena é definida como a restrição de pessoas que podem ter se exposto a uma doença contagiosa e o distanciamento social é utilizado para reduzir as interações entre pessoas em uma comunidade, às quais podem estar infectadas, mas ainda não foram identificadas com a doença.

$\mathrm{O}$ isolamento e o distanciamento social exigiram que as atividades de lazer fossem repensadas para se adequar à nova realidade imposta ao mundo. Nesse contexto, houve uma preocupação quanto às repercussões dessas medidas na vida da população. Embora haja recomendações quanto aos hábitos a serem adquiridos para uma vida saudável, a pandemia evidenciou a precariedade e vulnerabilidade da sociedade quanto 
aos cuidados físicos e psicológicos para lidar com situações extremas como uma pandemia.

Nesse contexto, a pandemia pode ter repercussões psicológicas que impactam negativamente a saúde mental. Situações tais como o medo, frustração, tédio, a perda da rotina e sensação de isolamento afetam as pessoas durante a pandemia (BROOKS et al. 2020). No estudo de Johnson; Saletti-Cuesta; Tumas (2020), durante a pandemia também se observou o sentimento de medo, angústia, responsabilidade, solidão, vulnerabilidade e descontrole. Ferreira et al. (2020) investigaram sobre ansiedade, depressão e estresse com intuito de descrever indicadores de saúde mental durante a pandemia por COVID-19 no Brasil. A partir dos resultados, nota-se que a intolerância à incerteza desempenha um papel relevante no processo de saúde mental durante a fase inicial da pandemia.

Segundo Justo-Henriques (2020, p. 298-306),

[...] a adoção de comportamentos saudáveis e preventivos é essencial para diminuir a propagação de doenças pandêmicas. Estes devem ser adequados à sintomatologia e vias de transmissão da doença. [...] Em conjunto com as medidas comportamentais preventivas e a comunicação clara, precisa e atempada, considera-se fundamental fomentar as redes de suporte social na comunidade e promover um sentimento de união, assim como providenciar apoio psicológico adequado às necessidades desde uma fase inicial da epidemia ou pandemia.

Em situações onde não há uma vacina ou tratamento farmacológico a mudança de comportamento é a estratégia principal com o intuito de evitar contágio e propagação da doença (JUSTO-HENRIQUES, 2020). Para atenuar o medo e apreensão quanto ao perigo de contágio, medidas preventivas específicas como lavagem das mãos e distanciamento social demonstraram um efeito protetor contra sintomas de estresse, ansiedade e depressão (ALKHAMEES et al., 2020).

Além da saúde mental enquanto dimensão do ser humano a ser analisada em relação ao período de pandemia, há também o lazer. Nesse sentido, considera-se o lazer 
enquanto necessidade humana. Não há um conceito único sobre o que é o lazer, contudo há uma construção do lazer enquanto contraposição ao trabalho. Muitas vezes associado à "improdutividade". Ao refletir sobre o lazer como necessidade humana, pode-se considerar que as necessidades humanas são finitas e variam conforme a cultura e o momento histórico (GOMES, 2014). Contudo,

[...] é cada vez mais evidente que a compreensão de lazer como uma esfera oposta ao trabalho não vem conseguindo problematizar as complexidades e as dinâmicas que marcam as múltiplas dimensões da vida coletiva em diferentes âmbitos e contextos, notadamente neste século XXI [...] o lazer representa a necessidade de fruir, ludicamente, as incontáveis práticas sociais constituídas culturalmente. Essa necessidade concretiza-se na ludicidade e pode ser satisfeita de múltiplas formas, segundo os valores e interesses dos sujeitos, grupos e instituições em cada contexto histórico, social e cultural. Por isso, o lazer precisa ser tratado como um fenômeno social, político, cultural e historicamente situado. [...] Concebido enquanto uma produção cultural humana, o lazer constitui relações dialógicas com a educação, com o trabalho, com a política, com a economia, com a linguagem e com a arte, entre outras dimensões da vida social, sendo parte integrante e constitutiva de cada coletividade (GOMES, 2014, p. 7 - 12).

A partir de Gomes (2014) nota-se que o lazer faz parte de uma construção histórica, a qual pode trazer mudanças quanto a sua forma de manifestação e que está transversal a outras dimensões da vida humana. Desse modo, não pode ser reduzida a uma mera contraposição ao trabalho.

Ainda, na Constituição Federal de 1988 , no Art. $6^{\circ}$ consta o direito ao lazer como um direito social. Desse modo são "direitos sociais a educação, a saúde, a alimentação, o trabalho, a moradia, o transporte, o lazer, a segurança, a previdência social, a proteção à maternidade e à infância, a assistência aos desamparados, na forma desta Constituição" (BRASIL, 1988). Durante a pandemia, o direito à saúde e ao lazer torna-se um desafio a ser enfrentado, de modo a também garantir a segurança contra a COVID-19.

Desse modo, tem-se como motivação de pesquisa compreender como as mudanças geradas pela pandemia repercutiram na vida das pessoas, de modo particular, em relação à saúde mental e ao lazer. A situação inédita e inesperada que se colocou 
com a pandemia gerou um cenário de incertezas que afetou a população em todo o mundo.

O objetivo deste trabalho é analisar como saúde mental e lazer foram impactados durante a pandemia por COVID-19. Para isso foi realizada uma revisão de literatura em artigos produzidos durante o ano de 2020. A metodologia utilizada foi pesquisa bibliográfica em artigos acadêmicos relacionados ao lazer e saúde mental referente ao período de pandemia de 2020 .

As revisões de literatura permitem conhecer a literatura científica sobre determinado assunto. Nesse sentido, visualizar o que já foi escrito sobre um assunto, aspectos que foram abordados, lacunas que podem abrir perspectivas para estudos futuros. Dessa forma, verificar as possibilidades de estudos e também as limitações (FLICK, 2013; PRODANOV, 2013; LIMA; MIOTO, 2007).

Ao longo de 2020, inúmeras comemorações tradicionais no Brasil e no mundo foram canceladas ou modificadas para serem transmitidas virtualmente pela Internet, sem a presença de público. Em dezembro de 2020, no Brasil o cenário foi de significativa diminuição do distanciamento social, onde a maior parte da população retomou atividades de lazer fora do ambiente doméstico. Natal e Réveillon também precisaram ser comemorados de modo a reduzir a quantidade de pessoas próximas, bem como as grandes festas tradicionais.

Devido ao aumento de casos de COVID-19 no Brasil e em outros países, houve estados brasileiros que para as festas de fim de ano intensificaram as restrições sanitárias, tais como Alagoas, Ceará, Rio Grande do Norte e São Paulo, dentre outros. De modo geral, são medidas para suspender eventos em massa e festivos durante Natal e Ano Novo com intuito de evitar aglomerações. Em Alagoas foram proibidas festas com mais de 300 pessoas, bem como as queimas de fogos para o Réveillon. Em São 
Paulo foi decretado em dias específicos (25, 26 e 27 de dezembro de 2020; 1, 2 e 3 de janeiro de 2021) o fechamento de shoppings, bares, restaurantes, academias de ginástica e qualquer tipo de evento público (HERCULANO, 2020; RIO GRANDE DO NORTE, 2020; PRADO, 2020; BATISTA, 2020).

Ainda em dezembro de 2020 iniciou-se a vacinação em diferentes países do mundo. Em 8 de dezembro o Reino Unido foi o primeiro país a vacinar sua população contra a COVID-19. Sendo que uma mutação ainda mais contagiosa foi detectada no país, levando a medidas de restrição de entrada e saída de pessoas que passaram pela região. Outros países como Estados Unidos (início em 14/12), Canadá (início em 14/12), Arábia Saudita (início em 17/12), China (meados de novembro), Sérvia (início em 24/12), México (início em 24/12), Chile (início em 24/12), dentre outros países. No Brasil, em dezembro, ainda não havia previsão para o início da vacinação (CNN BRASIL, 2020).

Nesse sentido, para proporcionar cuidados com a saúde mental e aumentar a sensação de bem-estar, há pessoas que buscam a prática de atividades de lazer. Podemse citar inúmeras atividades artísticas, físico-esportivas e intelectuais, tais como cinema, filmes, séries, redes sociais, leituras, jogos, práticas religiosas/espirituais, atividades físicas em casa ou em academia, esportes, festas, pintura, jardinagem, culinária, lazer na natureza (CASTILHO; RIBEIRO; UNGHERI, 2020; MONTENEGRO; QUEIROZ; DIAS, 2020; MAYOR; SILVA; LOPES, 2020).

Conforme uma pesquisa realizada pelo Instituto Península (2020a), com 7.773 profissionais de educação básica do Brasil, no período de 13 de abril a 14 de maio de 2020. Através de questionário online, foi perguntado sobre como estavam se sentindo a maior parte do tempo. Os resultados mostraram que os (as) participantes estavam: $67 \%$ ansiosos (as), 36\% entediados (as), 38\% cansados (as), 34\% estressados (as), 35\% 
sobrecarregados (as), 27\% frustrados (as), 17\% depressivos (as), 19\% solitários (as), $23 \%$ calmos (as) $9 \%$ alegres, $8 \%$ felizes, $7 \%$ satisfeitos (as), $6 \%$ entusiasmados (as), $3 \%$ realizados (as). Sobre a preocupação com a saúde mental, eles afirmaram: 17,0\% não estou preocupado (a); 34,2\% estou um pouco preocupado (a); $28,2 \%$ estou muito preocupado (a); 20,6\% estou totalmente preocupado (a).

Esta pesquisa do Instituto Península (2020b) foi continuada ao longo de 2020. No período de 20 de julho a 14 de agosto de 2020, participaram 2.779 respondentes a um questionário online. Sobre como estavam se sentindo na maior parte do tempo houve modificações: $64 \%$ ansiosos, $26 \%$ entediados, $46 \%$ cansados, $42 \%$ estressados, 53\% sobrecarregados, $34 \%$ frustrados, $20 \%$ depressivos, $18 \%$ solitários, $10 \%$ calmos, 5\% alegres, $5 \%$ felizes, $5 \%$ satisfeitos, $4 \%$ entusiasmados, $2 \%$ realizados. Sobre a saúde mental houve variações quanto aos percentuais observados em maio de 2020. Conforme os dados dos (as) participantes, foi observado: $12 \%$ não estou preocupado (a); $34 \%$ estou um pouco preocupado (a); $34 \%$ estou muito preocupado (a); $20 \%$ estou totalmente preocupado (a). Com base nos dados, é possível visualizar maior frequência de sentimentos negativos, em relação a sentimentos positivos, bem como um aumento desses sentimentos negativos e diminuição de sentimentos positivos na segunda etapa da pesquisa.

Vale ressaltar como o trabalho realizado no ambiente doméstico cria uma realidade de fusão entre a vida profissional, familiar e íntima. Os limites de horas de trabalho também se alteram nesse movimento, uma vez que o (a) trabalhador (a) que estiver com os aparatos tecnológicos a seu dispor pode ser mais requisitado (a) a estar disponível para realizar atividades que antes se encerravam com a saída de seu local físico de trabalho. Além de precisar de mais tempo para preparar seu material de 
trabalho, em casos como os (as) profissionais da educação, em especial os professores (as).

Nessa perspectiva, na pesquisa realizada pelo Instituto Península (2020a), foi perguntado na percepção desses (as) profissionais quais aspectos da vida melhoraram ou pioraram devido à pandemia. Os resultados mostram que 57\% consideraram que piorou muito às atividades de lazer e cultura; $30 \%$ consideraram que piorou um pouco; $8 \%$ consideraram que ficou igual; $4 \%$ consideraram que melhorou um pouco; $1 \%$ considerou que melhorou muito.

Sobre as atividades que os (as) professores (as) afirmaram dedicar mais tempo estão:66\% atividades domésticas, $62 \%$ trabalhar em casa nas atividades escolares, $43 \%$ lazer, 27\% apoiar os (as) filhos (as) nas tarefas escolares, 25\% atividade de autoconhecimento e autocuidado, $22 \%$ atividades físicas em casa. Conforme os dados apresentados, a maioria dos (as) professores (as) afirmaram dedicar mais tempo às atividades domésticas e ao trabalho (INSTITUTO PENÍNSULA, 2020a).

Sobre os recursos que têm apoiado os professores durante a pandemia foram apontados os seguintes: $70 \%$ ficar com a família, $56 \%$ assistir a TV, filmes e séries, $50 \%$ estudar, $42 \%$ ler livros, $41 \%$ conversar com amigos (as) e colegas, $39 \%$ trabalhar, $38 \%$ cozinhar, $35 \%$ buscar apoio na religião, 32\% assistir lives, $20 \%$ praticar atividade física, $16 \%$ praticar atividades de autoconhecimento e autocuidado (INSTITUTO PENÍNSULA, 2020b). Com base nos dados, há atividades de lazer presentes no cotidiano dos (as) professores que dão suporte à vivência do período de distanciamento social.

A seguir, alguns estudos abordam sobre a prática de exercícios físicos, sendo essa uma das atividades de lazer, dentre muitas outras que fazem parte do cotidiano das pessoas e que também se relaciona com os cuidados sobre a saúde mental e física. Sobre 
a prática de atividades físicas, segundo a Organização Mundial da Saúde (OMS), recomenda-se a prática de 150 minutos de atividades físicas aeróbicas moderadas semanalmente ou 75 minutos de atividades físicas aeróbicas vigorosas semanalmente, ou mesmo a combinação de ambas. Além disso, há recomendações para adultos de 18 ou mais, a atividade física inclui tempo de atividade física de lazer, transporte (por exemplo, caminhada e ciclismo), ocupacional (por exemplo, trabalho), atividades domésticas, brincadeiras, jogos, esportes ou exercícios planejados, em atividades diárias, familiares e comunitárias (WHO, 2010).

No estudo de Piza et al. (2020) foi analisada a prática de atividade física de lazer de pessoas com e sem doenças crônicas não transmissíveis. Foram analisados dados de 719 pessoas maiores de 18 anos de idade, em São Paulo. Os dados foram coletados no período de abril de 2017 a abril de 2018 por meio de entrevista em atendimentos realizados em unidades de saúde, das quais 70,1\% tinham doenças crônicas não transmissíveis. Os dados mostraram a prevalência da inatividade. Dentre as pessoas sem doença crônica não transmissível, 76,5\% (114 mulheres) eram inativas e 65,2\% (43 homens) eram inativos. Dentre as pessoas com doença crônica não transmissível, 70,5\% (266 mulheres) e 61,7\% (67 homens) eram inativos.

Dias et al. (2020) investigaram a prática de exercícios físicos e esportes no lazer de adultos em São Paulo de 2006 a 2016. Foram analisados dados de 21.357 pessoas do Sistema de Vigilância de Fatores de Risco e Proteção para Doenças Crônicas por Inquérito Telefônico (VIGITEL). Ao longo dos anos foi observado aumento da prática de exercícios físicos nos homens de 49,3\%, em 2006 para 56,0\%, em 2016. Nas mulheres houve mudança de $31,7 \%$, em 2006, para 40,8\%, em 2016. A faixa etária mais ativa está entre os 18 a 24 anos de idade (65\%) e 25 a 34 anos de idade (56,8\%), em 2016. A faixa menos ativa está entre 65 anos ou mais $(37,2 \%)$. Os autores observaram 
que ao longo dos anos houve diminuição da prática de modalidades como caminhada e futebol e o aumento de ginásticas de 2006 a 2016.

Gomes et al. (2019) compararam as barreiras para atividade física entre mulheres participantes e não participantes de um programa de exercícios físicos da Atenção Básica de Saúde em São Paulo. Participaram 222 em cada grupo e a maioria tinha mais de 60 anos. As barreiras mais citadas pelas mulheres não participantes foram a falta de companhia, falta de energia, sentir-se cansada ou desmotivada, lugar apropriado para se exercitar em casa e falta de dinheiro.

Freire et al. (2014) buscaram determinar os fatores associados à prática regular de atividade física. Participaram do estudo 763 adolescentes, 841 adultos e 740 idosos de Minas Gerais. Os dados foram obtidos por meio de questionário em visitas domiciliares. Foi identificado menor nível de atividade física com o aumento da idade e maior nível de atividade entre homens independentemente da idade e com maior escolaridade. Entre os adolescentes foi identificada a prevalência de jovens ativos entre aqueles que não fumavam.

Farias Júnior et al. (2012) buscaram identificar fatores associados à prática de exercícios entre adolescentes. A amostra foi composta por 2.874 estudantes, de 14 a 19 anos de idade, em João Pessoa, Paraíba. Os dados foram obtidos por meio de questionário. Os resultados mostraram que pouco mais da metade dos adolescentes eram fisicamente ativos $(50,2 \%)$, os jovens do sexo masculino eram mais ativos que o sexo feminino $(66,3 \%)$. Fatores que também contribuíram para a prática de exercícios foram a maior escolaridade dos pais e participar de aulas de educação física.

No trabalho de García-Puello et al. (2018) foram avaliados os níveis de atividade física em universitários. Participaram 601 estudantes, da cidade de Barranquilla, que responderam um questionário sobre variáveis sociodemográficas e 
autopercepção de saúde. Também foi realizado o cálculo do índice de massa corporal e aplicado o Teste de Classificação de Sedentarismo de Pérez-Rojas-Garcia. Os resultados mostraram alta prevalência de inatividade física $(61,6 \%)$. Os níveis de atividade física de acordo com o gênero também se evidenciam, onde as mulheres são menos ativas que os homens.

Cevada et al. (2012) compararam resiliência, qualidade de vida e ansiedade de 17 ex-atletas de alto rendimento de ginástica artística, 15 ex-atletas de outros esportes e 30 indivíduos não atletas, com idades entre 18 e 45 anos de idade, na cidade do Rio de Janeiro. Foram utilizados os seguintes instrumentos: Inventário de Depressão de Beck, Inventário de Ansiedade Traço e Estado (IDATE T e E), Escala de Resiliência e Questionário de Qualidade de Vida SF-36. Os resultados mostraram que os ex-atletas apresentaram maior resiliência, independente da modalidade praticada e da idade. Também apresentaram menor ansiedade em relação aos índices apresentados por não atletas. De modo que, a prática de exercício contribui para a saúde mental de praticantes de esportes.

Dessa forma, os estudos apresentaram resultados que apontam a inatividade ou baixa frequência de atividades físicas da população em diferentes contextos e em alguns é evidenciada a diferença de gênero quanto à frequência de atividade física, sendo mais frequente entre os homens. Neste trabalho também serão apresentados trabalhos que abordam sobre o lazer e atividades físicas, tendo como foco o período de pandemia.

Assim, este artigo aborda sobre trabalhos acadêmicos relacionados ao lazer e à saúde mental durante a pandemia. A seguir, o artigo está estruturado apresentando a metodologia, de modo a abordar como foi realizada a escolha dos artigos que compõe esta pesquisa. Nos resultados e discussões são elencados os trabalhos selecionados e 
foram organizados em duas categorias para abordar sobre saúde mental e sobre lazer e a COVID-19. Por fim, são apresentadas as considerações finais.

\section{Metodologia}

Para a construção desta revisão de literatura foi utilizado como procedimento metodológico uma pesquisa bibliográfica. Foi realizado um levantamento de artigos para compreender como a saúde mental e o lazer foram impactados durante o período de pandemia por COVID-19 (FLICK, 2013; PRODANOV, 2013; LIMA, MIOTO, 2007). As bases de dados consultadas foram SciELO e Scopus. Os critérios de inclusão aplicados foram: artigos que abordam sobre saúde mental ou lazer durante a pandemia; pesquisas realizadas em 2020; artigos em português, inglês ou espanhol. Não foram selecionados preprints e trabalhos que não eram especificamente sobre saúde mental ou lazer.

Nas bases de dados foram utilizados os seguintes descritores: COVID-19, coronavírus, pandemia, lazer, saúde mental, exercício físico, atividade física. Nas buscas de artigos sobre saúde mental foram consultadas as bases SciELO e Scopus. Na SciELO pela busca: (COVID-19 OR pandemia OR coronavírus) AND saúde mental foram obtidos 48 resultados. Na base Scopus pela busca: (COVID-19 OR pandemic OR coronavirus) AND mental health foram obtidos 272 resultados, utilizando a Psicologia como subárea. As buscas foram realizadas na primeira semana de dezembro de 2020.

Nas buscas de artigos sobre lazer e atividade física foram consultadas a base SciELO e a revista Licere, no volume 23, número 3, publicado em setembro de 2020. Na base Scielo pela busca: (COVID-19 OR pandemia OR coronavírus) AND (exercício físico OR atividade física OR lazer) foram obtidos 15 resultados. 
A partir da leitura dos resumos e posterior leitura dos artigos na íntegra foram selecionados 21 artigos para serem analisados. Sobre saúde mental e COVID-19, foram analisados doze artigos: cinco artigos foram obtidos pela SciELO e sete artigos obtidos pela Scopus. Sobre lazer, atividade física e COVID-19 foram analisados nove estudos: cinco foram obtidos pela SciELO e quatro artigos da revista Licere.

\section{Resultados e Discussões}

A Tabela 1 mostra os artigos selecionados para análise. Os artigos foram divididos conforme duas categorias: saúde mental e COVID-19 e lazer e COVID-19.

\section{Tabela 1: Artigos Selecionados para Análise}

\begin{tabular}{|c|c|c|}
\hline \multicolumn{3}{|l|}{ Saúde mental e COVID-19 } \\
\hline Título do artigo & Autores & Revista \\
\hline $\begin{array}{l}\text { The psychological impact of COVID-19 pandemic } \\
\text { on the general population of Saudi Arabia }\end{array}$ & $\begin{array}{l}\text { ALKHAMEES } \text { et al., } \\
2020\end{array}$ & Comprehensive Psychiatry \\
\hline $\begin{array}{l}\text { Relato de tristeza/depressão, } \\
\text { nervosismo/ansiedade e problemas de sono na } \\
\text { população adulta brasileira durante a pandemia de } \\
\text { COVID-19. }\end{array}$ & BARROS et al., 2020 & $\begin{array}{l}\text { Epidemiologia e Serviços } \\
\text { de Saúde }\end{array}$ \\
\hline Impacto psicossocial do isolamento durante & & \\
\hline pandemia de covid-19 na população brasileira: & $\begin{array}{l}\text { BEZERRA et al., } \\
2020\end{array}$ & Saúde \& Sociedade \\
\hline análise transversal preliminar & & \\
\hline $\begin{array}{l}\text { COVID-19 e os impactos na saúde mental: uma } \\
\text { amostra do Rio Grande do Sul, Brasil }\end{array}$ & DUARTE et al., 2020 & Ciência \& Saúde Coletiva \\
\hline $\begin{array}{l}\text { Students under lockdown: Comparisons of } \\
\text { students' social networks and mental health before } \\
\text { and during the COVID-19 crisis in Switzerland }\end{array}$ & $\begin{array}{l}\text { ELMER; MEPHAM; } \\
\text { STADTFELD, } 2020\end{array}$ & PLoS ONE \\
\hline $\begin{array}{l}\text { Intolerance of uncertainty and mental health in } \\
\text { Brazil during the COVID-19 pandemic }\end{array}$ & $\begin{array}{l}\text { FERREIRA et al. } \\
2020\end{array}$ & Suma Psicológica \\
\hline $\begin{array}{l}\text { Emociones, preocupaciones y reflexiones frente a } \\
\text { la pandemia del COVID-19 en Argentina }\end{array}$ & $\begin{array}{l}\text { JOHNSON; } \\
\text { SALETTI-CUESTA; } \\
\text { TUMAS, } 2020\end{array}$ & Ciência \& Saúde Coletiva \\
\hline
\end{tabular}

Validation of depression, anxiety and stress scales (DASS-21): Immediate psychological responses of students in the e-learning environment

Ansiedade, depressão e estresse em estudantes
LAN; LONG; HANH, International Journal of 2020

Higher Education

MAIA,; DIAS, 2020 Estudos de Psicologia 
universitários: o impacto da COVID-19

Mental Health Problems during the COVID-19

Pandemics and the Mitigation Effects of Exercise:

A Longitudinal Study of College Students in

China

Impact of the COVID-19 pandemic on mental health and quality of life among local residents in Liaoning province, China: a cross-sectional study

Prevalence and socio-demographic correlates of psychological health problems in Chinese adolescents during the outbreak of COVID-19

Lazer e COVID-19

Título do artigo

Perspectivas em psicologia do esporte e saúde mental sob a pandemia de COVID-19

Distanciamento Social e Tempo Livre: Paradoxos Vivenciados por Estudantes da Universidade Estadual de Minas Gerais no Âmbito do Lazer

Lazer Doméstico em Tempos de Pandemia da COVID-19

Prática de atividade física em meio à pandemia da COVID-19: estudo de base populacional em cidade do sul do Brasil

A pandemia da COVID-19 e as mudanças no estilo de vida dos brasileiros adultos: um estudo transversal, 2020

Physical activity in periods of social distancing due to COVID-19: a cross-sectional survey

\section{CLEMENTE;}

STOPPA, 2020

CROCHEMORE-

SILVA et al., 2020

Autores

BARREIRA;

TELLES

FILGUEIRAS, 2020

CASTILHO;

RIBEIRO;

UNGHERI, 2020

MALTA et al., 2020

MARTINEZ et al., 2020
Epidemiologia e Serviços de Saúde

\section{Revista}

Psicologia: Ciência \& Profissão

LICERE - Revista do Programa de Pósgraduação Interdisciplinar em Estudos do Lazer

LICERE - Revista do Programa de Pósgraduação Interdisciplinar em Estudos do Lazer

Ciência \& Saúde Coletiva

Ciência \& Saúde Coletiva
(Campinas)

International Journal

Environmental Research

Public Health

International Journal

Environmental Research

Public Health

European Children

Adolescent \& Psychiatry

Perspectivas sobre o Lazer das Mulheres com a Pandemia do Novo Coronavírus: Reflexões a partir dos Dados da Pesquisa “O Lazer no Brasil Representações e Concretizações das Vivências Cotidianas"

Arte como Estratégia de Coping em Tempos de Pandemia

Lazer em Tempos de Distanciamento Social: Impactos da Pandemia de COVID-19 nas Atividades de Lazer de Universitários na Cidade de Macapá (AP)
MAYOR; SILVA; LOPES, 2020

LICERE - Revista do Programa de Pósgraduação Interdisciplinar em Estudos do Lazer

MEDEIROS et al., 2020

Revista Brasileira de Educação Médica

MONTENEGRO; QUEIROZ; DIAS, 2020
LICERE - Revista do Programa de Pósgraduação Interdisciplinar em Estudos do Lazer 
Nas subseções a seguir os estudos foram analisados em duas categorias: Saúde mental e COVID-19 e Lazer e COVID-19.

\section{Saúde Mental e COVID-19}

Nesta seção foram analisados doze estudos relacionados à saúde mental e COVID-19 (BEZERRA et al., 2020; ZHANG;MA, 2020; MAIA; DIAS, 2020; BARROS et al., 2020; DUARTE et al., 2020; JOHNSON; SALETTI-CUESTA, TUMAS, 2020; FERREIRA et al. 2020; ALKHAMEES et al., 2020; ZHANG et al., 2020; LAN; LONG; HANH, 2020; ZHOU et al., 2020; ELMER; MEPHAM; STADTFELD, 2020).

Bezerra et al. (2020) realizaram um estudo com o objetivo de caracterizar o perfil da população brasileira em isolamento social e identificar preditores de estresse psicossocial. A pesquisa foi quantitativa, descritiva e analítica, realizada de 10 a 12 de abril de 2020, com dados coletados através de questionário online. Participaram 3.836 pessoas das cinco regiões do Brasil. Os resultados apontam que 63,4\% consideraram que o sono foi modificado; $42,3 \%$ sentiram sintomas físicos sem motivo aparente durante o isolamento social; $58,6 \%$ afirmaram que esses sintomas dificultaram o desempenho em atividades diárias. Dentre os (as) participantes que apresentaram tristeza e preocupação com a pandemia, 65,5\% estavam fazendo atividades como exercício físico, práticas religiosas e outras atividades lúdicas.

No estudo realizado por Zhang e Ma (2020) o objetivo foi investigar o impacto imediato da pandemia por COVID-19 na saúde mental e qualidade de vida de chineses com 18 anos ou mais de idade. Através de questionário online, os dados foram coletados de janeiro a fevereiro de 2020 e houve 263 participantes. Os resultados mostraram que $52,1 \%$ dos (as) participantes se sentiram horrorizados (as) e apreensivos 
(as) durante a pandemia. Sobre a saúde mental, 67,7\% dos (as) participantes relataram que estavam prestando mais atenção à saúde mental após a pandemia. Ainda, $62 \%$ dos (as) participantes relataram que estavam gastando mais tempo para descansar, 64,2\% afirmaram que estavam gastando mais tempo para relaxar e 59,7\% afirmaram que estavam gastando mais tempo para se exercitar.

Maia e Dias (2020) analisaram os níveis de depressão, ansiedade e estresse em estudantes universitários portugueses em relação ao período pandêmico em 2020 e comparativo a períodos anteriores à pandemia. Foram obtidas duas amostras: a amostra 1 em fevereiro/março de 2018, e em fevereiro/março de 2019, totalizando com 460 participantes; e a amostra 2 em março de 2020, com 159 participantes. Foi utilizada a escala Depression, Anxiety and Stress Scales (DASS-21). Os resultados confirmaram que o período pandêmico teve um impacto negativo e gerou aumento significativo de perturbação psicológica (ansiedade, depressão e estresse) em relação a períodos normais.

Estudos recentes realizados durante a pandemia mostram que a saúde mental da população tem sido significativamente afetada e também corroboram que as mulheres têm apresentado maiores índices quanto à ansiedade, estresse e depressão, em relação aos homens (BARROS et al., 2020; DUARTE et al., 2020; JOHNSON; SALETTICUESTA; TUMAS, 2020; FERREIRA et al. 2020; ALKHAMEES et al.., 2020; ZHANG et al., 2020; LAN; LONG; HANH, 2020; ZHOU et al., 2020; ELMER; MEPHAM; STADTFELD, 2020).

Barros et al. (2020) analisaram a frequência de tristeza, nervosismo e alterações do sono durante a pandemia de COVID-19 na população brasileira. Os dados foram coletados de 24 de abril a 24 de maio de 2020. Foi utilizado questionário online e obteve 45.161 respondentes, de 18 a 60 anos ou mais de idade. O estudo teve 
participantes das cinco regiões do Brasil. Os resultados mostraram que 40,4\% das pessoas afirmaram se sentir tristes ou deprimidos muitas vezes ou sempre; $52,6 \%$ afirmaram se sentir ansiosos ou nervosos muitas vezes ou sempre; 43,5\% afirmaram ter problemas de sono iniciados durante a pandemia. Foi observado que tais sentimentos negativos tiveram maior frequência em pessoas que já tinham depressão. Ainda, os dados da pesquisa revelaram maior impacto psicológico da pandemia em mulheres, em relação aos homens.

Duarte et al. (2020) verificaram os fatores associados a sintomas de transtornos mentais em residentes do Rio Grande do Sul. A coleta de dados foi realizada de 8 a 23 de abril de 2020. Participaram 799 pessoas, com idade entre 18 e 75 anos. Foram utilizados como instrumentos um questionário socioeconômico, de distanciamento social e o Self-Report Questionnaire (SRQ-20). Os resultados mostraram o sexo como uma variável de risco indicada pela regressão logística. As evidências sugerem uma chance de 2,73 vezes maior entre as mulheres de apresentar um transtorno menor, em relação aos homens. Também o diagnóstico prévio de transtorno mental aumenta o risco quanto aos prejuízos em relação à saúde mental, bem como maior exposição a informações sobre morte e infectados.

Johnson; Saletti-Cuesta e Tumas (2020) realizaram uma pesquisa para explorar os sentimentos e as expectativas geradas pela COVID-19 na Argentina durante a pandemia. A pesquisa foi realizada em dois períodos: 23 a 25 de março de 2020, com 992 pessoas; e 30 de março a 3 de abril de 2020, com 418 pessoas. Foram feitas perguntas abertas e realizada uma análise de conteúdo. Dentre os resultados observados, as mulheres manifestaram em maior medida sentimentos de medo, angústia, sentimentos de responsabilidade, cuidados e valorização da interdependência, afetos e a possibilidade de introspecção e reflexão sobre a pandemia. Conforme os autores, a 
maior expressão de medo e angústia nas mulheres pode dar indícios de que a pandemia as afeta mais.

Ferreira et al. (2020) realizaram um estudo para investigar a relação entre intolerância à incerteza e desordens de saúde mental comuns. De 3 de abril a 6 de abril de 2020, foi utilizado questionário online com questões sociodemográficas, a Depression, Anxiety and Stress Scale (DASS-21) e a Reduced Intolerance Uncertainty Scale (IUS-12). Participaram 924 pessoas de Sergipe, Brasil. Os resultados mostraram maior probabilidade de escores de estresse, ansiedade e depressão acima da mediana em mulheres.

Alkhamees et al. (2020) avaliaram o grau de impacto psicológico durante a pandemia na Arábia Saudita. Os dados foram coletados de 2 a 5 de abril de 2020 e teve 1.160 participantes. Os instrumentos utilizados foram a Impact of Event Scale-Revised (IES-R) e DASS-21 e dados sociodemográficos. Os resultados mostraram que aproximadamente um quarto dos participantes experimentou impacto psicológico moderado a grave, respectivamente: impacto psicológico $(23,6 \%)$; sintomas depressivos $(28,3 \%)$; sintomas de ansiedade (24\%) e sintomas de estresse $(22,3 \%)$. Mulheres e estudantes apresentaram maiores níveis relacionados à escala de DASS-21. Tais resultados quanto à escala DASS-21 convergem com o estudo de Ferreira et al. (2020).

Zhang et al. (2020) avaliaram o impacto da COVID-19 na saúde mental de estudantes universitários chineses. De fevereiro a março de 2020 participaram 66 estudantes universitários. Os dados coletados foram sobre informações demográficas, atividade física, emoções negativas, qualidade do sono e nível de agressividade. As mortes por COVID-19 tiveram impacto negativo direto na qualidade geral do sono; e impacto indireto nas emoções negativas como estresse e ansiedade. Observou-se que a atividade física relaciona-se ao alívio diretamente às emoções negativas gerais. Em 
relação ao gênero, as mulheres sofreram um maior impacto psicológico com o surto de COVID-19. Ainda, os autores apontam que se recomenda a necessidade de dormir bem e fazer exercícios físicos.

No estudo de Lan; Long e Hanh (2020) foi validada a DASS-21 para observar a saúde mental em estudantes universitários vietnamitas e a reação psicológica em ambiente de ensino online. Foi realizada de 6 a 20 de março de 2020, com cerca de 2000 estudantes. Nos resultados, nas estudantes mulheres os fatores sociodemográficos e impacto psicológico estão significativamente associados a um maior nível de ansiedade.

Zhou et al. (2020) avaliaram sintomas depressivos e de ansiedade em adolescentes chineses afetados pela COVID-19. No período de 8 de março a 25 de março de 2020 participaram 8.079 estudantes do ensino fundamental e médio, com idades entre 12 e 18 anos. Foram utilizados os seguintes instrumentos: Patient Health Questionnaire (PHQ-9) e Generalized Anxiety Disorder (GAD-7). Os resultados mostraram que índices importantes de sintomas depressivos (43,7\%), sintomas de ansiedade $(37,4 \%)$ e combinação de sintomas depressivos e de ansiedade $(31,3 \%)$ entre estudantes do ensino médio. Quanto ao gênero, as mulheres apresentaram maior fator de risco para sintomas depressivos e ansiosos.

No estudo de Elmer; Mepham e Stadtfeld (2020) foram analisadas as redes sociais e a saúde mental de estudantes universitários suíços antes da pandemia (dados obtidos desde 2018, com 212 estudantes) e durante a pandemia (abril de 2020, com 54 estudantes). Nas redes sociais foram analisadas a interação, amizade, apoio social, estudo conjunto e indicadores de saúde mental (depressão, ansiedade, estresse, solidão). No período de pandemia, os níveis de estresse, ansiedade, solidão e sintomas depressivos aumentaram. Aponta-se que a falta de interação e suporte emocional e o 
isolamento físico relacionaram-se com trajetórias negativas de saúde mental. Com base no gênero, os resultados mostraram que as estudantes mulheres apresentaram trajetórias de saúde mental piores em relação à integração social e estressores relacionados à COVID-19.

Desse modo, a partir de estudos recentes, observam-se os impactos da pandemia em sua fase inicial e as repercussões sobre a saúde mental da população. Estudos em diferentes países mostram que independentemente do local onde a pandemia se estabeleceu, houve alterações significativas na saúde mental da população, principalmente em relação ao estresse, ansiedade e depressão. Para isso, também há a presença de testes psicológicos utilizados para identificar tais frequências de sintomas relacionados à saúde mental.

Ainda, outros sentimentos e manifestações de sofrimento mental podem ser observados. Contudo, em grande medida são relatados sentimentos negativos quanto à vivência de incerteza e de medo sobre a doença, bem como de mudanças no cotidiano. Outro aspecto a ser destacado em relação aos estudos é sobre o gênero e como a saúde mental do publico feminino tem sido afetada negativamente durante esse período.

Desse modo, é necessário considerar os impactos das políticas públicas frente ao isolamento social e sobre a dimensão afetiva das pessoas. Nesse sentido, são importantes estratégias para melhorar a saúde da população, considerando as desigualdades sociais e de gênero (JOHNSON; SALETTI-CUESTA; TUMAS, 2020).

Sobre possíveis lacunas quanto aos estudos, aponta-se o curto espaço de tempo em que foram realizados, em período inicial da pandemia, e representatividade populacional que também limita a generalização dos resultados. 


\section{Lazer e COVID-19}

Nesta seção foram analisados quatro estudos referentes ao lazer e a COVID-19 de forma geral (MEDEIROS et al., 2020; CLEMENTE; STOPPA, 2020; MONTENEGRO; QUEIROZ; DIAS, 2020; CASTILHO; RIBEIRO; UNGHERI, 2020) e cinco diretamente relacionados a atividades físicas e COVID-19 (CROCHEMORESILVA et al., 2020; BARREIRA; TELLES; FILGUEIRAS, 2020; MALTA et al., 2020; MAYOR; SILVA; LOPES, 2020; MARTINEZ et al., 2020).

Durante a pandemia, algumas alternativas de lazer emergiram fortemente como forma de tentar atenuar o abrupto distanciamento social imposto à sociedade. Medeiros et al. (2020) apresentaram um relato de experiência sobre atividades artísticas realizadas com estudantes de Medicina durante o período de pandemia participantes do grupo Estudo de Literatura e Arte na Medicina (Elam). Os autores apontam que a saúde mental dos estudantes necessita de estratégias para lidar com as situações de extrema ansiedade. Foram desenvolvidas atividades de produção textual (crônicas, poesia), pintura em aquarela, artes plásticas. Os temas abordados nos textos foram: amor, envelhecer, pecado e religiosidade, ciclo da vida, câncer, caos, sabedoria, mortalidade, tempo, olhar, ver, regionalismo. A iniciativa de criação do grupo está relacionada à necessidade de cuidados em relação à saúde mental de estudantes de medicina. Conforme apontam estudos, há uma prevalência significativa de manifestação de sofrimento psíquico em estudantes dessa área, e a pandemia é uma situação que pode aumentar o estresse e ansiedade.

Clemente e Stoppa (2020) apresentaram um estudo sobre vivências de lazer presentes durante a pandemia. Foi realizada pesquisa bibliográfica e documental, entre 10 de julho a 10 de agosto. Segundo Clemente e Stoppa (2020, p. 462), 
clubes, museus e centros culturais, associativismo, entre outras. Em contrapartida, houve um incremento em grande escala no uso de plataformas digitais, como YouTube, Netflix, Globoplay, redes sociais, canais de notícias, televisão, assim como advento de programas para realização de encontros online ou reuniões, como Zoom, Meets, entre outros.

O mundo virtual e suas possibilidades se tornaram o modo mais seguro de muitas pessoas manterem contato. A grande oferta das famosas "lives" foi uma das formas de artistas e criadores de conteúdo virtual ampliar seus canais de comunicação. As redes sociais ganharam ainda mais visibilidade como meio de disseminar conteúdo, bem como as plataformas de streaming para oferta de filmes, séries, documentários e outros conteúdos.

Clemente e Stoppa (2020, p. 475) destacam que

[...] não somente a restrição de uso de espaços e equipamentos de lazer se traduz em uma barreira sociocultural identificada no lazer em tempos de Covid-19, que é refletida primeiramente no fechamento dos parques, museus, clubes, teatros, cinemas, praias, e demais locais, que estão gradualmente retornando seus funcionamentos com devidos protocolos sanitários, mas também as limitadas estruturas dos lares para vivência de lazer para a maioria das pessoas se traduz em uma barreira.

Ainda, Clemente e Stoppa (2020) apontam sobre o fato do trabalho durante a pandemia ter em determinados casos aderido ao home Office. Essa modalidade de trabalho já existia, mas se disseminou durante a pandemia.

Montenegro; Queiroz e Dias (2020) buscaram identificar impactos nas formas de lazer de estudantes. Foi aplicado questionário online e participaram 456 estudantes universitários de Macapá-AP. Os resultados mostraram aumento na "residencialização" e "virtualização" do lazer, para isso aumentou o uso da Internet, jogos online, assistir lives e filmes. Antes do distanciamento social as atividades de lazer citadas foram: 63,4\% lazer na natureza; 44,5\% praças, shoppings, museus;42,5\% família e amigos; $39 \%$ cinema; $37,1 \%$ festas; $31,8 \%$ esportes; $27,4 \%$ exercício físico; $24,1 \%$ restaurantes e bares; $14,9 \%$ leitura. Durante o distanciamento social: $89,9 \%$ internet; $67,3 \%$ filmes; 
64,9\% música; 49,8\% assistir lives; 47,6\% jogos online; 46,9\% assistir televisão; 41,9\% leitura; $26,1 \%$ exercício físico.

Os autores também questionaram se durante o distanciamento social foram desenvolvidas atividades novas: $78,1 \%$ afirmaram que não; $21,9 \%$ afirmaram que sim. As atividades desenvolvidas foram: cozinhar, participar de aulas de idiomas, estudos, leitura, cursos de marcenaria, exercício físico, jogos na Internet, musicalização, construção de hortas, jardinagens, compras na Internet e educação econômica (MONTENEGRO; QUEIROZ; DIAS, 2020).

Montenegro, Queiroz e Dias (2020, p. 14-15) discutem que na vivência do distanciamento social ampliou-se a

[...] virtualidade como mediadora das vivências de lazer, a qual, por um lado, pode gerar experiências estéticas, críticas e criativas nesse contexto, mas também reforçar a desigualdade de acesso, dadas as condições díspares de disponibilidade de meios virtuais para a prática do lazer. [...] A virtualidade impacta o lazer na medida em que podemos ter diversas referências como práticas de diversão, mesmo sem o contato físico com elas. A virtualidade ampliou nosso acesso a práticas esportivas; estilos musicais; filmes; séries, revelando um novo padrão para vivência do lazer na contemporaneidade.

Castilho; Ribeiro e Ungheri (2020) realizaram uma pesquisa com estudantes universitários. Os dados foram coletados de 14 a 21 de abril de 2020 e obteve 936 respostas de estudantes da UEMG, Ibirité, através de questionário online. Sobre os tipos de atividades de lazer ou bem-estar feitas durante a pandemia predominou a visualização de filmes e séries, uso de redes sociais, leitura, jogos e palestras. De acordo com os dados coletados, a seguir são descritos quantos participantes escolheram atividades de lazer: 750 (Interesses artísticos - assistir filmes/séries); 693 (Interesses virtuais - navegar em redes sociais); 624 (Interesses intelectuais - leituras; jogos de cartas; jogos de tabuleiro; ouvir palestras); 463 (Encontro com pessoas da família na mesma casa, ou virtualmente via redes sociais); 407 (Práticas religiosas/espirituais); 379 (Atividades físicas em casa - danças, ginásticas, localizadas, exercícios de meditação); 
308 (Interesses virtuais - jogos virtuais); 289 (Interesses manuais - pinturas, jardinagem, culinária, tricô).

Castilho; Ribeiro e Ungheri (2020) apontam que o aumento significativo de consumo de Internet não se refere apenas às atividades de lazer, mas também ao uso para o trabalho, estudo e compras online. No caso de estudantes universitários também se destacam as aulas remotas. Os autores apontam que dentre os (as) participantes cerca de $10 \%$ afirmaram não ter acesso suficiente à Internet. Desse modo, também apontando a necessidade levar em conta os aspectos de desigualdade de acesso aos meios digitais.

Segundo Castilho; Ribeiro e Ungheri (2020, p. 116),

[...] uma outra consequência direta do recolhimento social diz respeito à gestão do tempo. Repentinamente, os afazeres domésticos e o trabalho formal - para aqueles que continuaram trabalhando de maneira remota - se fundiram gerando uma sobrecarga substancial. Além disso, podemos citar igualmente o cuidado com os familiares mais idosos, bem como a incumbência extra relativa às crianças (e bebês) que tiveram, tal qual todos os cidadãos, suas rotinas alteradas. Dados do estudo evidenciam que uma parcela significativa, $30,2 \%$ dos respondentes, considera que esteja com sobrecarga de atividades domésticas e cuidados com crianças devido ao distanciamento social provocado pela pandemia.

Sobre atividades físicas durante a pandemia, considerando também as mesmas como um modo de lazer, os estudos de Crochemore-Silva et al. (2020), Barreira; Telles e Filgueiras (2020), Malta et al. (2020), Martinez et al. (2020) e Mayor; Lopes e Silva (2020) trazem considerações sobre sua importância em situações de isolamento e distanciamento social.

Crochemore-Silva et al. (2020) descreveram a prática de atividade física de lazer em meio a pandemia do COVID-19 na cidade de Bagé, no Rio Grande do Sul, avaliando diferenças relacionadas ao nível de distanciamento social e as desigualdades em termos de sexo e escolaridade. Os dados foram coletados de 7 a 9 de maio de 2020 e participaram 377 pessoas adultas através de questionário online. Os resultados 
mostraram que $24,4 \%$ dos (as) participantes estavam praticando atividade física durante a pandemia.

Foram observadas diferenças significativas de atividade física entre os sexos, $37,1 \%$ dos homens afirmaram praticar atividade física de lazer durante a pandemia, enquanto nas mulheres o índice foi de $16,9 \%$. Sobre o grau de escolaridade na amostra geral observou-se a prevalência de atividade física de lazer em 9,8\% dos (as) participantes com menor escolaridade e 50,9\% com nível superior completo. Sobre o local de prática de atividade física, 53,5\% praticavam em casa; 38,9\% ao ar livre e 7,8\% em outros lugares. Sobre o acompanhamento de profissional, 64,8\% praticavam atividade sem acompanhamento de profissional. Os indivíduos que mais relataram atividade física de lazer estavam em distanciamento social intermediário (CROCHEMORE-SILVA et al., 2020).

Ainda, Crochemore-Silva et al. (2020, p. 4254) apontam que

[...] cerca de um quarto dos participantes relataram a prática de atividades físicas como ginásticas, esportes, caminhadas ou corridas no seu lazer durante a pandemia, sendo majoritariamente realizada em casa e sem orientação de profissionais de Educação Física. [...] Desde o início da pandemia e do distanciamento social, a importância da atividade física foi enfatizada em textos de opinião, posicionamentos e pouco baseada em evidências científicas. A base argumentativa indicava preocupação com a redução da atividade física no período.

Com base nisso, os autores colocam em questão quais aspectos podem interferir nas práticas de atividades físicas, para além de enfatizar o discurso sobre a necessidade dessas atividades. Desse modo, afirmam a necessidade de "um olhar social e humanizado ao tema" (CROCHEMORE-SILVA et al., 2020, p. 4256). Nesse sentido, também destacam os dados da pesquisa que mostram que os homens durante a pandemia apresentaram maior índice de atividade física que as mulheres. A reflexão apresentada também aponta o aspecto das mulheres socialmente se ocuparem com mais atividades, dentre elas atividades domésticas, cuidados com outras pessoas e trabalho. 
Essas barreiras sociais também afetam o tempo de lazer das mulheres. Outro aspecto social enfatizado pelos pesquisadores está na diferença de escolaridade que se mostrou quanto ao acesso às atividades físicas de lazer, a qual se relaciona com aspectos socioeconômicos que permitem o acesso a essas atividades.

Barreira; Telles e Filgueiras (2020) buscaram compreender as relações entre saúde mental e prática esportiva, de exercício e/ou atividade física no período de pandemia da COVID-19. Os autores refletem que a prática de atividade física no confinamento fornece ao praticante o restabelecimento de parâmetros de tempo e espaço em sua rotina. Com base na observação de estudos empíricos, os autores apontam que a frequência da rotina de exercícios tem incidência no processo de regulação do humor, contudo salientam que o excesso de atividade também pode ser prejudicial para o bemestar. A partir de dados de levantamentos realizados no início da pandemia, o exercício moderado (até 3 vezes por semana) está melhor associado com o bem-estar.

Ainda, a adaptação da intensidade de prática de exercícios físicos deve ser adequada à rotina de cada sujeito conforme suas possibilidades. Outro aspecto levantado pelos autores, a partir das evidências dos benefícios da prática de exercícios para o bemestar e saúde mental, é sobre a parceria entre psicólogos e profissionais de Educação Física. Desse modo, essa atuação multidisciplinar pode proporcionar a prescrição correta de treinamentos para contribuir para o bem-estar e saúde mental, para além da sugestão de caminhadas ou frequentar uma academia (BARREIRA; TELLES; FILGUEIRAS, 2020).

No estudo de Malta et al. (2020) descreveram as mudanças nos estilos de vida, quanto ao consumo de tabaco, bebidas alcoólicas, alimentação e atividade física, no período de restrição social consequente à pandemia da COVID-19. Os dados foram coletados por meio de questionário online, de 24 de abril a 24 de maio de 2020. A 
pesquisa foi realizada pela Fundação Instituto Oswaldo Cruz (Fiocruz) em parceria com a Universidade Federal de Minas Gerais (UFMG) e a Universidade Estadual de Campinas (Unicamp). Participaram 45.161 pessoas com 18 ou mais anos de idade, do Brasil. Sobre a prática de atividade física, durante a pandemia foi observado um percentual de $12,0 \%$. Antes da pandemia, entre os homens (33\%) a prevalência foi maior que em relação às mulheres $(27,6 \%)$. Durante a pandemia, houve redução em ambos os sexos e os homens (14\%) mantiveram a prevalência de atividade física em relação às mulheres (10,3\%). Entre os adultos jovens (18 a 29 anos), o percentual passou de $32,6 \%$ antes da pandemia, para 10,9\% durante a pandemia. Entre adultos (30 a 39 anos), antes da pandemia eram $31,0 \%$ e durante a pandemia $10,6 \%$. Os idosos (60 anos ou mais) passaram de 30,4\% para 14,2\% quanto à prática de atividade física.

Outros resultados da pesquisa se referem ao aumento de tempo assistindo televisão, ao uso de computador ou tablet e alimentação. $\mathrm{O}$ aumento médio de tempo assistindo televisão foi de 1 hora e 45 minutos, relação ao período anterior à pandemia. Em relação ao uso de computador ou tablet, houve um aumento médio de 1 hora e 30 minutos. Sendo o maior tempo de uso observado entre adultos jovens (18 a 29 anos), com cerca de 7 horas e 15 minutos. Ainda, aumento de consumo de alimentos processados. A partir desses achados, os autores apontam para o aumento de comportamentos de risco à saúde durante a pandemia (MALTA et al., 2020).

Além disso, os dados em Malta et al. (2020), mostram que as mulheres apresentaram percentuais de atividade física menores comparados aos homens. Tendose em vista que os autores apresentam dados descritivos sobre a população brasileira, reforça-se que podem embasar reflexões sobre quais aspectos estão relacionados a esses índices, bem como já foi citado anteriormente o fato das mulheres em sua jornada de 
atividades também incluir atividades domésticas e de cuidados que diminuem suas atividades de lazer.

Martinez et al. (2020) verificaram as mudanças de hábitos de participantes brasileiros praticantes de atividades físicas no período de distanciamento social durante a pandemia por COVID-19. Também foram analisados os níveis de ansiedade e depressão. Foi utilizado questionário sociodemográfico e a Escala de Depressão de Ansiedade Hospitalar de 14 itens. O questionário foi aplicado de 11 a 15 de maio de 2020. Participaram 1.613 pessoas, com idade acima de 18 anos. Os resultados mostraram que $79,4 \%$ dos (as) participantes confirmaram que a pandemia teve um impacto grande ou muito grande em suas atividades físicas. Muitas pessoas tiveram que interromper ou diminuir a frequência de atividades. Para continuar as atividades os (as) participantes tiveram aulas online, acesso a conteúdo por meio de vídeo ou lives na Internet, monitoramento remoto de personal trainer. Dentre os (as) participantes, 48,8\% apresentaram sintomas de depressão e $82,6 \%$ com sintomas de ansiedade. A ansiedade foi mais frequente entre mulheres, jovens adultos e pessoas com ensino superior. Ainda, os (as) participantes que sentiram maior impacto do distanciamento social nas atividades físicas tenderam a ter maior prevalência de sintomas de depressão e ansiedade.

Mayor; Silva e Lopes (2020) objetivaram refletir sobre as práticas de lazer e pandemia e analisaram as diferenças percebidas entre homens e mulheres. As autoras discutem a partir de dados de pesquisa publicada em 2017, denominada "O lazer no Brasil: representações e concretizações das vivências cotidianas", que contou com 2400 participantes, com idade acima de sete anos de idade dos 26 estados da Federação e do Distrito Federal. Foi utilizado questionário estruturado, com perguntas abertas e fechadas. Foram analisados interesses físico-esportivo, turístico, social, artístico, 
manual e intelectual. Aqui serão abordados os dados referentes ao interesse físicoesportivo. Com base nas perguntas, o que faz durante a semana e no fim de semana, conforme o sexo foi observado que o interesse físico-esportivo dos homens durante a semana foi de $15,6 \%$ e no fim de semana de $31,5 \%$; e $7,9 \%$ das mulheres mostraram durante a semana interesse físico-esportivo e no fim de semana 10,3\%. As autoras apontam que essa diferença de interesse entre homens e mulheres reflete o tratamento desigual em relação ao direito à prática esportiva.

Mayor; Silva e Lopes (2020) ao analisarem o filtro "trabalhando" como forma de compreender sobre a divisão sexual do trabalho e sua relação com o lazer, observouse que durante a semana $11,7 \%$ dos homens apresentaram interesse físico-esportivo e 24,4\% no fim de semana. Em relação às mulheres, durante a semana, 5,0\% apresentam interesse físico-esportivo e 5,0\% no final de semana. Nota-se que a diferença entre homens e mulheres que trabalham apresenta-se significativa. Ainda, ao analisar as diferenças entre homens e mulheres, ao utilizar os filtros "trabalhando", "casado (a) civilmente" e "união estável", pode-se observar a diferença de modo ainda mais claro. Durante a semana, 9,5\% dos homens casados apontaram interesse físico-esportivo e $20,5 \%$ no fim de semana. Durante a semana, 4,9\% das mulheres casadas apontaram interesse físico-esportivo e 4,3\% no fim de semana. Sobre homens e mulheres em união estável, durante a semana, 11,0\% dos homens apontaram interesse físico-esportivo e $28 \%$ no fim de semana. Em relação às mulheres, durante a semana, 4,5\% apresentaram interesse físico-esportivo e 3,5\% no fim de semana.

Dessa forma, as autoras apontam diferenças consideráveis sobre as vivências de lazer de homens e mulheres, especialmente nas relações com o trabalho e a vida conjugal. Nesse sentido, reflete-se sobre as condições impostas às mulheres que impedem ou diminuem as possibilidades das mesmas vivenciarem atividades de lazer, 
que se relacionam a sobrecarga de trabalho e afazeres domésticos. Conforme os dados apresentados, para os homens o vínculo empregatício e o status civil não impactaram quanto às vivências de lazer (MAYOR; SILVA; LOPES, 2020).

Em suma, a partir dos estudos analisados, os dados em Clemente e Stoppa (2020), Montenegro; Queiroz e Dias (2020) e Castilho; Ribeiro e Ungheri (2020) convergem quanto ao aumento de atividades relacionadas à virtualização do lazer (assistir TV, filmes, séries, lives) que também se mostram mais presentes que outras atividades como leitura, atividades físicas e práticas de autocuidado.

Os resultados da pesquisa de Malta et al. (2020) corroboram com os estudos de Montenegro; Queiroz e Dias (2020) e Crochemore-Silva et al. (2020) que mostram a diminuição das atividades físicas em consequência das medidas de distanciamento e isolamento social. O fenômeno da virtualização também pode ser entendido no aumento de horas assistindo televisão e conectado a equipamentos digitais, uma vez que o lazer se limitou ao ambiente doméstico e as TDIC disponíveis nas residências. Contudo, tal fenômeno apresenta aspectos positivos e negativos.

O termo Tecnologias da Informação e Comunicação (TIC) é relacionado a dispositivos eletrônicos e tecnológicos tais como computador, Internet, smartphone, tablet. Atualmente, esse termo também se refere a tecnologias como televisão e jornal, por exemplo. O termo Novas Tecnologias ou Tecnologias Digitais da Informação e Comunicação (TDIC) é utilizado para se referir a tecnologias mais recentes (COSTA; DUQUEVIZ; PEDROZA, 2015).

A alta exposição às TDIC devido ao distanciamento tem sua função de diminuir distâncias e permitir o diálogo mesmo com a pandemia, mas coloca em questão aspectos quanto ao acesso às tecnologias e como uma grande parcela da população ainda não têm condições econômicas de estar conectada à Internet de forma adequada. 
Com relação ao acesso às TIC no Brasil, segundo a Pesquisa Nacional por Amostra de Domicílios Contínua 2018, realizada pelo Instituto Brasileiro de Geografia e Estatística (IBGE), no Brasil, em 2018, 79,1\% dos domicílios brasileiros tinham acesso à Internet. Contudo, a diferença entre o acesso na área urbana $(83,8 \%)$ e a área rural $(49,2 \%)$. Sobre os motivos para a não utilização de Internet se destacaram: a falta de interesse $(34,7 \%)$; acesso a Internet era caro $(25,4 \%)$, nenhum morador sabia usar a Internet $(24,3 \%)$. Nos domicílios da área rural um dos principais motivos para a não utilização foi a indisponibilidade do serviço de Internet (20,8\%). A principal finalidade para o uso da Internet no Brasil foi para enviar e receber mensagens de texto, voz ou imagem $(95,7 \%)$, conversar por chamadas de vídeo ou voz $(88,1 \%)$, assistir a vídeos, inclusive programas, séries e filmes $(86,1 \%)$, enviar e receber e-mail $(63,2 \%)$. Sobre a posse de microcomputador, tablet, telefone fixo, celular e televisão, a seguir são descritas as porcentagens de domicílios onde se contatou a existência de tais dispositivos: microcomputador $(41,7 \%)$, tablet $(12,5 \%)$; telefone fixo $(28,4 \%)$, celular (93,2\%), e televisão $(96,4 \%)$ (IBGE, 2020a; 2020b).

A partir dos dados do IBGE, há uma parcela significativa da população com acesso às TIC, contudo tais dados revelam que ainda nem todos têm acesso a Internet e a equipamentos, tais como microcomputador, tablet e celular. No período da pandemia por COVID-19 isso se mostrou um dos grandes aspectos que revelam as desigualdades sociais e econômicas quanto ao acesso a serviços essenciais que passaram a ser disponibilizados virtualmente, bem como ao lazer e ao ensino remoto. Segundo Menezes e Francisco (2020), em relação ao acesso à educação durante a pandemia, são visíveis as diferenças de acesso em relação às TDIC, tanto para professores quanto para estudantes. Essa experiência também se tornou fonte de estresse para esse público, bem como dificuldades de adaptação. 
Em relação ao gênero, nota-se que o impacto já expressivo no tempo de lazer das mulheres antes da pandemia tende a se acirrar durante a pandemia, uma vez que trabalho e ambiente doméstico assumem uma nova realidade para muitas mulheres que passaram a trabalhar em casa. Desse modo, a pandemia tornou as linhas que separam as dimensões da vida profissional e pessoal ainda mais tênues, e também aumentou a carga de trabalho para determinados grupos sociais como as mulheres.

Nesse sentido, os estudos analisados relacionados ao lazer durante a pandemia apontam repercussões consideráveis sobre o modo de vida das pessoas. O cenário marcado por quarentena, medidas de isolamento social e distanciamento social influenciou as formas de socialização e as modalidades de lazer para se adaptar a um maior tempo no ambiente doméstico. Por isso, a necessidade de lazer expressa também formas de lidar com as repercussões dessas medidas sobre a saúde mental das pessoas.

Ao analisar dados anteriores à pandemia referentes à prática de exercícios físicos, observa-se que durante a pandemia a tendência foi o aumento da inatividade física de modo a prevalecer atividades virtuais. Nesse cenário, ressalta-se que aspectos sociais, econômicos e de acesso também impactaram diretamente essas vivências, sendo que há uma parcela da população onde os direitos sociais à saúde e ao lazer precisam de maior efetividade de políticas públicas durante e após a pandemia.

Ainda, as demandas de cuidado e também a realidade do ensino remoto levou muitas mulheres a terem que dedicar mais tempo aos (às) filhos (as) para manterem os estudos ao longo de 2020. Sobre como a pandemia afetou o cotidiano, principalmente das mulheres, Guizzo; Marcello e Müller (2020) apresentam cenas do novo cotidiano imposto pela pandemia às famílias. Na cena 5 uma mãe apresenta um relato sobre como o home schooling apresenta-se como uma situação estressante, a qual é difícil dar conta 
devido ao ensino remoto e ao home office. Dentre outras cenas que apresentam às mudanças no cotidiano devido à pandemia.

Sobre possíveis lacunas quanto aos estudos, assim como foi visualizado nos estudos relacionados à saúde mental aponta-se o curto espaço de tempo em que foram realizados, em período inicial da pandemia, e sobre representatividade populacional que também limita a generalização dos resultados. Por essa razão, são necessários estudos que envolvam outras fases da pandemia para estabelecer comparativos quanto aos aspectos sobre a saúde mental e sobre o lazer que foram observados nos estudos acima apresentados.

\section{Considerações Finais}

Este estudo teve o objetivo de abordar sobre os impactos da pandemia por COVID-19 na saúde mental e no lazer. Considera-se que essas duas dimensões referentes ao ser humano apresentam-se entrelaçadas e que são influenciadas por determinantes sociais, culturais, econômicos e psicológicos. Com base no cenário de incerteza e medo gerado pela pandemia, há a necessidade de medidas estratégicas que contribuam para a promoção e cuidados referentes à saúde mental da população mundial. Os estudos no Brasil e no mundo mostram como as pessoas tiveram sua saúde mental afetada negativamente, além das atividades de lazer terem se restringido de modo inesperado.

Desse modo, os estudos abordados ao longo deste trabalho enfatizam também como o ambiente digital passou a ser uma grande aposta para suprir para determinada parcela da sociedade a necessidade de lazer e trabalho, bem como apontar que isso desnudou a face da exclusão digital no Brasil e no mundo. Ainda, grupos vulneráveis, como as mulheres, têm sua saúde mental e lazer mais prejudicados em face à pandemia. 
Por essa razão, é necessário colocar em evidência estratégias que promovam qualidade de vida e cuidados para diminuir as desigualdades sociais, que se mostram ainda mais intensas em períodos de crise generalizada.

As pesquisas analisadas neste artigo sobre a pandemia são em grande parte com dados produzidos no primeiro semestre de 2020, também refletindo um curto espaço de tempo onde as pesquisas têm buscado analisar os impactos iniciais da pandemia da COVID-19. Em estudos futuros, pretende-se analisar os efeitos em longo prazo da pandemia e seus impactos sobre o lazer e saúde mental.

Assim, considera-se que a vivência do período de pandemia apresentou-se para a sociedade como um desafio que afetou as experiências relacionadas à saúde mental e ao lazer. Nesse processo há barreiras e possibilidades quanto ao uso de ambientes virtuais, bem como a busca por atividades que minimizem os aspectos negativos que a pandemia trouxe. Nesse sentido, iniciativas governamentais que estimulem espaços de lazer públicos, para atividades físicas, por exemplo, no cenário pós-pandemia podem contribuir para melhorar a qualidade de vida da população.

Por fim, durante o período de pandemia recomenda-se a prática de atividade de lazer no ambiente doméstico, levando em conta as possibilidades de cada pessoa para continuar a cuidar de sua saúde física e mental, sejam atividades físicas, manuais, intelectuais ou virtuais, por exemplo. $\mathrm{O}$ acesso à Internet devido à pandemia mostrou que a conectividade ainda é um dos problemas que nossa sociedade ainda enfrenta e as diferenças sociais produzem um cenário de desigualdades abismais, onde o direito ao à saúde e ao lazer ainda não é exercido plenamente pela população, especialmente a mais vulnerável. Cenários de crise apenas evidenciam e desnudam essa realidade, apontando também a necessidade de políticas públicas para permitir a conectividade e acesso às tecnologias para a população. 


\section{Agradecimentos}

Ao Instituto Federal de Alagoas (IFAL) pelo apoio à qualificação profissional para realização do Doutorado em Educação.

\section{REFERÊNCIAS}

ALKHAMEES, A. A. et al. The psychological impact of COVID-19 pandemic on the general population of Saudi Arabia. Comprehensive Psychiatry, n. 102, 2020. DOI: http://doi.org/10.1016/j.comppsych.2020.152192.

BARREIRA, C. R. A., TELlES, T. C. B., FILGUEIRAS, A. Perspectivas em psicologia do esporte e saúde mental sob a pandemia de COVID-19. Psicologia: Ciência \& Profissão, v. 40, e243726, 2020, p. 1-14. DOI: https://dx.doi.org/10.1590/1982-3703003243726.

BARROS, M. B. A et al. Relato de tristeza/depressão, nervosismo/ansiedade e problemas de sono na população adulta brasileira durante a pandemia de COVID-19. Epidemiologia e Serviços de Saúde, Brasília, v. 29, n. 4, e2020427, 2020. DOI: http://doi.org/10.1590/s1679-49742020000400018.

BATISTA, R. Festas de réveillon com mais de 300 pessoas estão proibidas em Alagoas. G1 AL. Disponível em: http://g1.globo.com/al/alagoas/noticia/2020/12/03/festas-dereveillon-com-mais-de-300-pessoas-estao-proibidas-em-alagoas.ghtml. Acesso em: 27 dez. 2020.

BEZERRA, C. B. et al. Impacto psicossocial do isolamento durante pandemia de COVID-19 na população brasileira: análise transversal preliminar. Saúde \& Sociedade, v. 29, n. 4, dez, 2020. DOI: https://dx.doi.org/10.1590/s0104-12902020200412.

BRASIL. Constituição (1988). Constituição da República Federativa do Brasil, 1988. Disponível em:

http://www.planalto.gov.br/ccivil_03/constituicao/constituicao.htm. Acesso em: 2 dez. 2020.

BROOKS, S. K. et al. The psychological impact of quarantine and how to reduce it: rapid review of the evidence, The Lancet, v. 395 (102227), p. 912-920. 2020. DOI: http://doi.org/10.1016/S0140-6736(20)30460-8.

CASTILHO, C. T.; RIBEIRO, S. P.; UNGHERI, B. O. Distanciamento Social e Tempo Livre: Paradoxos Vivenciados por Estudantes da Universidade Estadual de Minas Gerais no Âmbito do Lazer. Licere, v. 23, n. 3, p. 93-125, 2020. DOI: http://doi.org/10.35699/2447-6218.2020.25216.

CEVADA, T. et al. Relação entre esporte, resiliência, qualidade de vida e ansiedade. Revista de Psiquiatria Clínica, São Paulo, v. 39, n. 3, p. 85-89, 2012. DOI: http://doi.org/10.1590/S0101-60832012000300003. 
CLEMENTE, A. C. F.; STOPPA, E. A. Lazer Doméstico em Tempos de Pandemia da COVID-19. Licere, v. 23, n. 3, p. 460-484, 2020. DOI: http://doi.org/10.35699/24476218.2020 .25524 .

CNN BRASIL. Saiba quais são os países que já estão vacinando; Brasil está fora. Disponível em: http://www.cnnbrasil.com.br/saude/2020/12/24/quais-os-paises-que-jacomecaram-a-vacinacao-contra-a-covid-19. Acesso em: 27 dez. 2020.

COSTA, S. R. S.; DUQUEVIZ, B. C.; PEDROZA, R. L. S. Tecnologias Digitais como instrumentos mediadores da aprendizagem dos nativos digitais. Psicologia Escolar e Educacional, v. 19, n. 3, 603-610. 2015. DOI: http://doi.org/10.1590/21753539/2015/0193912.

CROCHEMORE-SILVA, I. et al. Prática de atividade física em meio à pandemia da COVID-19: estudo de base populacional em cidade do sul do Brasil. Ciência \& Saúde Coletiva, v. 25, n, 11, Nov. 2020. DOI: http://doi.org/10.1590/1413812320202511.29072020 .

DIAS, T. G. et al. Nível de atividade física no lazer em adultos paulistanos: uma análise de tendência de 2006 a 2016. Revista Brasileira de Epidemiologia, Rio de Janeiro, v. 23, e200099, 2020.

DUARTE, M. Q. et al. COVID-19 e os impactos na saúde mental: uma amostra do Rio Grande do Sul, Brasil. Ciência \& Saúde Coletiva, Rio de Janeiro, v. 25, n. 9, p. 34013411, sept. 2020. DOI: https://dx.doi.org/10.1590/1413-81232020259.16472020.

ELMER, T.; MEPHAM, K.; STADTFELD, C. Students under lockdown: Comparisons of students' social networks and mental health before and during the COVID-19 crisis in Switzerland. PLoS ONE, v. 15, n. 7, e0236337, 2020. DOI: http://doi.org/10.1371/journal.pone.0236337.

FARIAS JÚNIOR, J. C. et al. Prática de atividade física e fatores associados em adolescentes no Nordeste do Brasil. Revista de Saúde Pública, São Paulo, v. 46, n. 3, p. 505-515, jun., 2012. DOI: http://doi.org/10.1590/S0034-89102012005000031.

FERREIRA, D. C. S. et al. Intolerance of uncertainty and mental health in Brazil during the COVID-19 pandemic.Suma Psicológica, Bogotá, v. 27, n.1, p. 62-69, jun./dec., 2020. DOI: https://dx.doi.org/10.14349/sumapsi.2020.v27.n1.8.

FLICK, U. Introdução à metodologia da pesquisa: um guia para iniciantes. Porto Alegre: Penso, 2013.

FREIRE, R. S. et al. Prática regular de atividade física: estudo de base populacional no Norte de Minas Gerais, Brasil. Revista Brasileira de Medicina do Esporte, São Paulo, v. 20, n. 5, p. 345-349, oct. 2014.

GARCÍA-PUELLO, F. et al. Evaluación de los niveles de actividad física em universitarios mediante método directo. Revista de Salud Pública, v. 20, n. 5, sep./oct., 2018. DOI: http://doi.org/10.15446/rsap.V20n5.59003.

GOMES, C. L. Lazer: necessidade humana e dimensão da cultura. Revista Brasileira de Estudos do Lazer. Belo Horizonte, v. 1, n.1, p.3 - 20, jan./abr., 2014. 
GOMES, G. A. O. et al. Barreiras para prática de atividade física entre mulheres atendidas na Atenção Básica de Saúde. Revista Brasileira de Ciências do Esporte, Porto Alegre, v. 41, n. 3, p. 263-270, sept. 2019.

GUIZZO, B. S.; MARCELlO, F. A; MULlER, F.. A reinvenção do cotidiano em tempos de pandemia. Educação e Pesquisa, São Paulo, v. 46, e238077, 2020. DOI: https://dx.doi.org/10.1590/s1678-4634202046238077.

HERCULANO, D. Novo decreto estadual mantém restrições sanitárias vigentes Ceará. Governo do Estado do Ceará. Disponível em: http://www.ceara.gov.br/2020/12/04/novo-decreto-estadual-mantem-restricoessanitarias-vigentes-ceara/. Acesso em 27 dez. 2020.

IBGE (Instituto Brasileiro de Geografia e Estatística). PNAD Contínua TIC 2018: Internet chega a 79,1\% dos domicílios do país. 2020a. Disponível em: http://agenciadenoticias.ibge.gov.br/agencia-sala-de-imprensa/2013-agencia-denoticias/releases/27515-pnad-continua-tic-2018-internet-chega-a-79-1-dos-domiciliosdo-pais. Acesso em: 2 dez. 2020.

Uso de Internet, televisão e celular no Brasil. 2020b. Disponível em: https://educa.ibge.gov.br/jovens/materias-especiais/20787-uso-de-internet-televisao-ecelular-no-brasil.html. Acesso em: 2 dez. 2020.

INSTITUTO PENÍNSULA. Relatório de pesquisa de sentimento e percepção dos professores brasileiros nos diferentes estágios do Coronavírus no Brasil. Estágio Intermediário - Maio de 2020. 2020a Disponível em: http://institutopeninsula.org.br/wpcontent/uploads/2020/05/Covid19_InstitutoPeninsula_Fase2_at\%C3\%A91405-1.pdf. Acesso em: 21 nov. 2020.

Relatório de pesquisa de sentimento e percepção dos professores brasileiros nos diferentes estágios do Coronavírus no Brasil. Estágio controlado - Agosto de 2020. 2020b. Disponível em: http://institutopeninsula.org.br/wpcontent/uploads/2020/08/Sentimentos_-fase-3.pdf Acesso em: 21 nov. 2020.

IMPRENSA NACIONAL. Portaria ${ }^{\circ}$ 454, de 20 de março de 2020. Declara, em todo o território nacional, o estado de transmissão comunitária do coronavírus (covid19). Diário Oficial da União. 2020. Disponível em: http://www.in.gov.br/en/web/dou//portaria-n-454-de-20-de-marco-de-2020-249091587. Acesso em: 2 dez. 2020.

JOHNSON, M. C.; SALETTI-CUESTA, L.; TUMAS, N. Emociones, preocupaciones y reflexiones frente a la pandemia del COVID-19 en Argentina. Ciência \& Saúde Coletiva, 25, 2020. DOI: http://doi.org/10.1590/1413-81232020256.1.10472020.

JUSTO-HENRIQUES, S. Contributo da psicologia da saúde na promoção de comportamentos salutogénicos em pandemia. Psicologia, Saúde \& Doenças, Lisboa, v. 21, n. 2, p. 297-310, ago. 2020. DOI: https://dx.doi.org/10.15309/20psd210206.

LAN, H. T. Q.; LONG, N. T.; HANH, N. V. Validation of depression, anxiety and stress scales (DASS-21): Immediate psychological responses of students in the elearning environment. International Journal of Higher Education, v. 9, n. 5, 2020. DOI: http://doi.org/10.5430/ijhe.v9n5p125. 
LIMA, T. C. S.; MIOTO, R. C. T. Procedimentos metodológicos na construção do conhecimento científico: a pesquisa bibliográfica. Revista Katálysis, Florianópolis, v. 10, n. spe, p. 37-45, 2007. DOI: http://doi.org/10.1590/S1414-49802007000300004.

MAIA, B. R.; DIAS, P. C. Ansiedade, depressão e estresse em estudantes universitários: o impacto da COVID-19. Estudos de Psicologia (Campinas), Campinas, v. 37, e200067, 2020. DOI: http://doi.org/10.1590/1982-0275202037e200067.

MALTA, D. C. et al. A pandemia da COVID-19 e as mudanças no estilo de vida dos brasileiros adultos: um estudo transversal, 2020. Epidemiologia e Serviços de Saúde, Brasília, v. 29, n. 4, e2020407, 2020. DOI: .http://doi.org/10.1590/s167949742020000400026

MARTINEZ, E. Z. et al. Physical activity in periods of social distancing due to COVID-19: a cross-sectional survey. Ciência \& Saúde Coletiva, Rio de Janeiro, v. 25, supl. 2, p. 4157-4168, oct. 2020. DOI: http://doi.org/10.1590/1413812320202510.2.27242020.

MAYOR, S. T. S.; SILVA, M. S.; LOPES, C. G. Perspectivas sobre o Lazer das Mulheres com a Pandemia do Novo Coronavírus: Reflexões a partir dos Dados da Pesquisa "O Lazer no Brasil - Representações e Concretizações das Vivências Cotidianas". Licere, v. 23, n. 3, p. 163-189, 2020. DOI: .http://doi.org/10.35699/24476218.2020.25363

MEDEIROS, M. S. et al. A Arte como Estratégia de Coping em Tempos de Pandemia. Revista Brasileira de Educação Médica, Brasília, v. 44, supl. 1, e130, 2020. DOI: .http://doi.org/10.1590/1981-5271v44.supl.1-20200354

MINISTÉRIO da saúde. Primeiro caso de Covid-19 no Brasil permanece sendo o de 26 de fevereiro. 2020. Disponível em: http://www.gov.br/saude/ptbr/assuntos/noticias/primeiro-caso-de-covid-19-no-brasil-permanece-sendo-o-de-26-defevereiro. Acesso em: 02 dez. 2020.

MENEZES, S. K. O.; FRANCISCO, D. J. Educação em tempos de pandemia: aspectos afetivos e sociais no processo de ensino e aprendizagem. Brazilian Journal of Computers in Education (Revista Brasileira de Informática na Educação - RBIE), v. 28, p. 985-1012, 2020. DOI: https://dx.doi.org/10.5753/rbie.2020.28.0.985.

MONTENEGRO, G. M.; QUEIROZ, B. S.; DIAS, M. C. Lazer em Tempos de Distanciamento Social: Impactos da Pandemia de COVID-19 nas Atividades de Lazer de Universitários na Cidade de Macapá (AP). Licere, v. 23, n. 3, p. 1-26, 2020. DOI: http://doi.org/10.35699/2447-6218.2020.24785.

PRADO, M. Estado de SP só terá serviços essenciais durante Natal e Ano-Novo. CNN Brasil. Disponível em: http://www.cnnbrasil.com.br/nacional/2020/12/22/estado-de-spso-tera-servicos-essenciais-durante-natal-e-ano-novo. Acesso em: 27 dez. 2020.

PRODANOV, C. C. Metodologia do trabalho científico [recurso eletrônico]: métodos e técnicas da pesquisa e do trabalho. 2. ed. Novo Hamburgo: Feevale, 2013. 
PIZA, T. F. T. et al. Leisure physical activity of people with and without chronic noncommunicable diseases. Revista Brasileira de Enfermagem, Brasília, v. 73, supl. 6, e20190615, 2020. DOI: https://dx.doi.org/10.1590/0034-7167-2019-0615.

RIO GRANDE DO NORTE, Governo do Estado. Medidas do governo. Disponível em: http://portalcovid19.saude.rn.gov.br/medidas/medidasdogoverno/. Acesso em: 27 dez. 2020.

WILDER-SMITH, A.; FREEDMAN, D. O. Isolation, quarantine, social distancing and community containment: pivotal role for old-style public health measures in the novel coronavirus (2019-nCoV) outbreak. Journal of Travel Medicine, v. 27, p. 1-4. DOI: .http://doi.org/10.1093/jtm/taaa020

WHO. World Health Organization. Global Recommendations on Physical Activity for Health. Genebra: World Health Organization. 2010. Disponível em: https://www.who.int/publications/i/item/9789241599979. Acesso em: 2 dez. 2020.

ZHANG, Y.; MA, Z. F. Impact of the COVID-19 pandemic on mental health and quality of life among local residents in Liaoning province, China: a cross-sectional study. International Journal Environmental Research Public Health, Basileia, v. 17, n. 7, p. 2381, 2020. DOI: http://doi.org/10.3390/ijerph17072381.

et al. Mental Health Problems during the COVID-19 Pandemics and the Mitigation Effects of Exercise: A Longitudinal Study of College Students in China. International Journal of Environmental Research and Public Health, v. 17, n. 10, 3722, 2020.DOI: http://doi.org/10.3390/ijerph17103722.

ZHOU, S. J. et al. Prevalence and socio-demographic correlates of psychological health problems in Chinese adolescents during the outbreak of COVID-19. European Children Adolescent \& Psychiatry, jun.; v. 29, n. 6, p. 749-758. 2020. DOI:10.1007/s00787-020-01541-4.

\section{Endereço da Autora:}

Suzy Kamylla de Oliveira Menezes

Avenida Menino Marcelo, $\mathrm{n}^{\circ}$ 1391, Cidade Universitária

Maceió - AL - 57.073-460

Endereço Eletrônico: suzy.kamylla@gmail.com 